\title{
Applications of Anti/Prooxidant Fullerenes in Nanomedicine along with Fullerenes Influence on the Immune System
}

\author{
Danijela Petrovic, ${ }^{1}$ Mariana Seke, ${ }^{2}$ Branislava Srdjenovic, ${ }^{3}$ and Aleksandar Djordjevic ${ }^{4}$ \\ ${ }^{1}$ Department of Natural Sciences and Mathematics, Faculty of Education Sombor, University of Novi Sad, 25000 Novi Sad, Serbia \\ ${ }^{2}$ Institute of Nuclear Sciences "Vinca", University of Belgrade, 11000 Belgrade, Serbia \\ ${ }^{3}$ Department of Pharmacy, Faculty of Medicine, University of Novi Sad, 21000 Novi Sad, Serbia \\ ${ }^{4}$ Department of Chemistry, Biochemistry and Environmental Protection, Faculty of Sciences, University of Novi Sad, \\ 21000 Novi Sad, Serbia
}

Correspondence should be addressed to Danijela Petrovic; petrovid@tcd.ie

Received 16 April 2015; Accepted 21 July 2015

Academic Editor: Subhrajit Saha

Copyright (C) 2015 Danijela Petrovic et al. This is an open access article distributed under the Creative Commons Attribution License, which permits unrestricted use, distribution, and reproduction in any medium, provided the original work is properly cited.

\begin{abstract}
Fullerenes are molecules that, due to their unique structure, have very specific chemical properties which offer them very wide array of applications in nanomedicine. The most prominent are protection from radiation-induced injury, neuroprotection, drug and gene delivery, anticancer therapy, adjuvant within different treatments, photosensitizing, sonosensitizing, bone reparation, and biosensing. However, it is of crucial importance to be elucidated how fullerenes immunomodulate human system of defense. In addition, the most current research, merging immunology and nanomedicine, results in development of nanovaccines, which may represent the milestone of future treatment of diseases.
\end{abstract}

\section{Introduction}

The aim of this review is to report the most recent progress on applications of fullerene $\mathrm{C}_{60}$ and its derivatives in nanomedicine, as well as the influence of fullerene nanoparticles on immune system. Being novel substances, fullerenes generate considerable interest particularly in terms of their toxicity, biokinetics, biodegradation, and possible immune responses. This paper emphasizes the fullerene's antioxidative properties, but also its prooxidative features, as well as the impact of fullerenes on the cells of innate and adaptive immunity.

The fullerene $\mathrm{C}_{60}$ due to its physicochemical properties has the ability to both scavenge and generate reactive oxygen species. Antioxidant capacity of $\mathrm{C}_{60}$ is based on highly delocalized $\pi$ double bond system functioning as a "free radical sponge" and quenching different free radical species more efficiently than conventional antioxidants $[1,2]$. Fullerenes may also induce prooxidant effects and this is likely to be dictated by the fullerene in question, the cell type being investigated, and the experimental setup [3-6]. The solubility of $\mathrm{C}_{60}$ in polar solutions is very low, which greatly limits its potential applications in medicine. However, due to the presence of double bonds, $\mathrm{C}_{60}$ can be easily modified with chemical groups that allow its better water solubility. In that way, water-soluble $\mathrm{C}_{60}$ derivatives expand their opportunities for various medical applications such as protection from radiation-induced injury, neuroprotection, drug and gene delivery, therapy against many diseases and processes, photosensitizing, sonosensitizing, bone reparation, and biosensing.

\section{Protection from Radiation-Induced Injury, Ionizing Radiation, and UVA}

The main event during exposure of living organisms to ionizing radiation is DNA damage and formation of DNA double-strand breaks. Two mechanisms are involved: direct damage of DNA by the radiation energy or indirect damage mediated through reactive oxygen species such as radicals, 
peroxides, and superoxides, produced during the water radiolysis. In the case of gamma radiation and $\mathrm{X}$-rays, where low linear energetic transfer is present, a predominant proportion of the radiation damage results from the indirect mechanism. Fullerenol $\mathrm{C}_{60}(\mathrm{OH})_{24}$ has been proven to be promising protector against ionizing radiation. Stankov et al. have shown better cell survival in fullerenol-pretreated irradiated leukemic cells and significant overexpression of antiapoptotic $\mathrm{Bcl}-2$ and $\mathrm{Bcl}-\mathrm{xL}$ genes as well as antioxidative cytoprotective genes such as GSTA4, MnSOD, NOS, CAT, and HO-1 [7]. Unlike ionizing radiation, UVA radiation has far less energy but it also affects cells in an oxygendependent manner. Cellular targets are various including DNA, proteins, and membranes. 8-Oxo-7,8-dihydroguanine has been identified in several cell types as the major DNA oxidation product of UVA radiation [8]. This ubiquitous DNA oxidation product can be produced by hydroxyl radical $(\bullet \mathrm{OH})$, singlet oxygen $\left({ }^{1} \mathrm{O}_{2}\right)$, one-electron oxidants, or peroxynitrite [9]. In the research of Eropkin and coworkers, different forms of fullerenols demonstrated dual activity. Fullerenols $\mathrm{C}_{60}(\mathrm{OH})_{18-24}$ and $\mathrm{C}_{60}(\mathrm{OH})_{30-38}$ showed a protective effect against UVA-induced phototoxicity as well as broad spectrum of antiviral activity in vitro against actual strains of human influenza virus $\mathrm{A}(\mathrm{H} 1 \mathrm{~N} 1)$ and $\mathrm{A}(\mathrm{H} 3 \mathrm{~N} 2)$, avian influenza $\mathrm{A}(\mathrm{H} 5 \mathrm{~N} 1)$, human herpes simplex virus, adenovirus, and respiratory-syncytial virus. Fullerenols did not show toxic effects toward human and animal cells of various tissue origins [10]. Kato et al. have used fullerene$\mathrm{C}_{60}$ /liposome complex as UVA protector. The complex of 250-500 ppm restored $\mathrm{HaCaT}$ keratinocytes viability after the UVA-irradiation of $10 \mathrm{~J} / \mathrm{cm}^{2}$. According to fluorescent immunostaining, $\mathrm{C}_{60}$ was mainly located around the outside of nuclear membrane without impairment of cell morphology [11]. Further, the complex was administered on the surface of three-dimensional human skin tissue model, rinsed out before each UVA-irradiation at $4 \mathrm{~J} / \mathrm{cm}^{2}$, and thereafter added again, followed by 19 -cycle repetition for 4 days (sum: $76 \mathrm{~J} / \mathrm{cm}^{2}$ ). Skin damage involved breakdown of collagen type I/IV, DNA strand cleavage, and pycnosis/karyorrhexis and was significantly reduced by the complex [12].

\section{Neuroprotection}

Oxidative stress on nervous tissue can produce damage by several interacting mechanisms, including increases in intracellular free $\mathrm{Ca}^{2+}$ and release of excitatory amino acids as well as excessive production of reactive oxygen species in the presence of "catalytic" iron or copper ions. Free radical reactions are also involved in the neurotoxicity of aluminum and in damage to the substantia nigra in patients with Parkinson's disease [13]. Oxidative stress generated in this regard causes physical damage to neurons by demyelination, mitochondrial dysfunction, microtubular damage, and apoptosis [14]. Ameliorating properties of fullerene derivatives on acetylcholinesterase (AChE) inhibition induced by organophosphates have been investigated by Ehrich and coworkers [15]. Organophosphorus compounds (OP) are widely used as insecticides and their primary mechanism of action is inhibition of AChE which is followed by cholinergic poisoning. Rapid AChE inhibition occurring after OP exposure has been reported to result in oxidative stress, as indicated by reduction in glutathione, increases in reactive oxygen species, and production of stress proteins [16]. Ehrich et al. used hen brain and human neuroblastoma SH-SY5Y cells as model systems. Cells were incubated with eight different derivatized fullerene compounds before challenge with paraoxon or diisopropylphosphorofluoridate (DFP). Activities of brain and $\mathrm{SH}-\mathrm{SY} 5 \mathrm{Y}$ AChE with OP compounds alone ranged from 55 to $83 \%$ lower than nontreated controls after paraoxon and from 60 to $92 \%$ lower than nontreated controls after DFP. Most of the incubations containing 1 and $10 \mu \mathrm{M}$ fullerene derivatives brought $\mathrm{AChE}$ activity closer to untreated controls, with improvements in AChE activity. The fullerene derivatives demonstrated significant antioxidant capability in neuroblastoma cells at $1 \mu \mathrm{M}$ concentrations. No fullerene derivative at $1 \mu \mathrm{M}$ significantly affected neuroblastoma cell viability [15]. The other group has generated nanocomplex of fullerene $\mathrm{C}_{60}$ formulated with poly( $\mathrm{N}$-vinyl pyrrolidine) (PVP) or poly(2-alkyl-2-oxazoline)s (POx) homopolymer and random copolymer. Tracking of the selected formulations during cellular uptake and their intracellular distribution were performed in catecholaminergic neurons. $\mathrm{C}_{60}-\mathrm{POx}$ and $\mathrm{C}_{60}-\mathrm{PVP}$ complexes exhibited similar physicochemical properties and antioxidant activities. $\mathrm{C}_{60}-\mathrm{POx}$ complex, but not $\mathrm{C}_{60}$-PVP complex, was efficiently taken up by neurons and attenuated the increase of intraneuronal superoxide induced by angiotensin II stimulation [17].

Bearing in mind that free radical injury has been specifically implicated in the pathogenesis of different neurodegenerative disorders, Vorobyov and coworkers have used amyloid- $\beta(\mathrm{A} \beta)$ rat model of Alzheimer's disease (AD) to study the effects of hydrated fullerene $\mathrm{C}_{60}\left(\mathrm{C}_{60} \mathrm{HyFn}\right)$. Interrelations between EEG frequency spectra from the frontal cortex and the dorsal hippocampus (CA1) were considered. Infusion of $\mathrm{A} \beta 1-42$ protein into the $\mathrm{CA} 1$ region two weeks before EEG testing decreased hippocampal theta predominance and eliminated cortical beta predominance observed in baseline EEG of rats infused with saline or with $\mathrm{C}_{60} \mathrm{HyFn}$ alone. In contrast, these $\mathrm{A} \beta 1-42$ effects were eliminated in rats pretreated with $\mathrm{C}_{60} \mathrm{HyFn}$. Further, to clear up the role of dopaminergic mediation in $\mathrm{AD}$, peripheral injection of a dopamine agonist, apomorphine, was applied. In rats infused with $\mathrm{C}_{60} \mathrm{HyFn}$ or A $\beta 1-42$ alone, APO attenuated the cortical beta predominance while pretreatment with $\mathrm{C}_{60} \mathrm{HyFn}$ decreased the apomorphine effect in the $\mathrm{A} \beta 1-42$-treated rats. Altogether, intrahippocampal injection of A $\beta 1-42$ dramatically disrupts cortical versus hippocampal EEG interrelations and pretreatment with $\mathrm{C}_{60} \mathrm{HyFn}$ eliminates this abnormality [18]. In another model against $\beta$-amyloid- $(\mathrm{A} \beta)(25-35-)$ induced toxicity toward Neuro-2A cells, scientists investigated $\mathrm{C}_{60}$ fullerene derivative incorporating poly(ethylene glycol) (PEG-C(60)-3) and its pentoxifylline-bearing hybrid (PTX-C(60)-2). PEG-C(60)-3 and PTX-C(60)-2 significantly reduced $\mathrm{A} \beta(25-35-)$ induced cytotoxicity, with comparable activities in decreasing reactive oxygen species and maintaining the mitochondrial membrane potential. $\mathrm{A} \beta(25-35)$ 
treatment caused adenosine monophosphate-activated protein kinase-associated autophagy. Cytoprotection by PEGC(60)-3 and PTX-C(60)-2 was partially diminished by an autophagy inhibitor, indicating that the caused autophagy and antioxidative activities protected cells from $\mathrm{A} \beta$ damage [19].

Glutamates are the carboxylate anions and salts of glutamic acid. Glutamate is the most abundant excitatory neurotransmitter which in higher concentration results in excitotoxicity causing degeneration of neurons and their death. Glutamate binds to metabotropic glutamate receptors (mGluRs) and triggers a signaling cascade. Detrimental role of group II mGluRs during hypoxic conditions has been described [20]. Giust et al. suggested that [60]fullerene hydrosoluble derivative through modulation of mGluRs could be protective against hypoxia. They used human neuroblastoma cells (SH-SY5Y) to evaluate the long time $(24,48$, and 72 hours) effects of the trans-3 isomer of [60]fullerene (t3ss). Low oxygen concentration $\left(5 \% \mathrm{O}_{2}\right)$ caused cell death, which was avoided by t3ss exposure in a concentration dependent manner [21].

Knowing that neural cells are terminally differentiated and that damaged neurons are difficult to regenerate, $\mathrm{C}_{60}$ derivatives could be helpful in solving this problem. In the study of Tsumoto and coworkers, water-soluble $\mathrm{C}_{60}$ derivatives are shown to have an enhancing effect on the neurite outgrowth. They used rat pheochromocytoma PC12 cells as a model of nerve cells. PC12 cells were treated with neurite growth factor (NGF) resulting in the induction of differentiation and the formation of neurites. Firstly, it was examined whether or not $\mathrm{C}_{60}$ derivatives have similar activity to NGF. However, no effects as seen with NGF were observed. Next, the effect of $\mathrm{C}_{60}$ derivatives on neurite outgrowth in NGF-treated PC12 cells was examined. PC12 cells that were treated with NGF plus $0-50 \mu \mathrm{M} \mathrm{C}_{60}$ derivative formed neurites and both neurite number and length of outgrowth increased in a dose-dependent manner, reaching a maximum at $25 \mu \mathrm{M}$ [22].

\section{Drug Delivery}

Designing multifunctionalized $\mathrm{C}_{60}$ systems able to be efficiently targeted to specific tissues, cross cell membranes, and delivery active agents is still an attracting challenge which involves multidisciplinary approach. In the study of Zhang and coworkers was developed a new kind of active targeting. Hyaluronic acid (HA) was grafted onto $\mathrm{C}_{60}$ and then combined with transferrin (Tf) to obtain a multifunctional drug delivery system ( $\left.\mathrm{HA}-\mathrm{C}_{60}-\mathrm{Tf}\right)$ with significant tumour targeting efficacy as well as capacity for photodynamic therapy. After this step, artesunate (AS) was adsorbed on HA-C ${ }_{60}$-Tf. MCF-7 cells and tumour-bearing murine model were used to evaluate antitumour efficacy. AS-loaded HA-C60-Tf showed enhanced antitumour efficacy in comparison with free AS in both cases. Furthermore, with laser irradiation in vivo, the relative tumour volume $(\mathrm{V} / \mathrm{V} 0)$ of $\mathrm{HA}-\mathrm{C}_{60}$-Tf/AS declined by half [23].

\section{Therapeutic Agents}

5.1. Antioxidant. Fullerenol $\left(\mathrm{C}_{60}(\mathrm{OH})_{24}\right.$ nanoparticles, FNP) is a symmetrical derivative of $\mathrm{C}_{60}$ with good water solubility. In aqueous solutions, it is in the form of poly anionic nanoparticles whose size distribution is in range between $20 \mathrm{~nm}$ and $200 \mathrm{~nm}$ with the largest number of measurements between $30 \mathrm{~nm}$ and $100 \mathrm{~nm}$ [24]. Srdjenovic et al. have determined its size distribution and $\zeta$-potential in cell culture RPMI 1640 medium supplemented with 10\% fetal bovine serum (FBS). According to their results, the size distribution of FNP nanoparticles was not affected by FBS and/or cell medium and formation of large particles was not induced but caused reduction in $\zeta$-potential of nanoparticles (from $-58 \mathrm{mV}$ to $-7,9 \mathrm{mV}$ ). The researchers also investigated the influence of FNP on Chinese hamster ovary cells (CHO-K1) survival, as well as antioxidant capacity of FNP in mitomycin C-treated cell line. It has been shown that activity of antioxidative enzymes was increased in dose-dependent manner. Further results confirmed that FNP did not induce genotoxic effects; on the contrary, antigenotoxic effects of FNP were confirmed in the experiment done on MMC-damaged CHO$\mathrm{K} 1$ cells in concentrations of 11-221.6 $\mu \mathrm{M}$ [25]. Fullerenol with its antioxidant activity can also mediate oxidative stressinduced senescence. Retinal pigment epithelium (RPE) cells and ARPE-19 cells were exposed to pulsed $\mathrm{H}_{2} \mathrm{O}_{2}$ stress for 5 days. Fullerenol protected the RPE cells, as it reduced the number of senescence positive cells, alleviated the depletion of cellular antioxidants, and reduced genomic DNA damage [26].

The results of Bal et al's study provide preliminary indication that hydrated nanoparticles of pristine $\mathrm{C}_{60}$ display the superior antioxidant activity necessary to effectively alleviate diabetic complications by elimination of testicular apoptosis and consequent histopathological abnormalities, thus resulting in elevation of testosterone level and increase of sperm content and motility [27]. In a quite different study, Baati et al. wanted to find out whether the lifespan can be prolonged. They administered $\mathrm{C}_{60}$ dissolved in olive oil $(0.8 \mathrm{mg} / \mathrm{mL})$ orally at reiterated doses $(1.7 \mathrm{mg} / \mathrm{kg}$ of body weight) to rats and demonstrated that it did not entail chronic toxicity but it almost doubled their lifespan. The effects of $\mathrm{C}_{60}$ olive oil solutions in an experimental model of $\mathrm{CCl}_{4}$ intoxication in rat strongly suggested that the effect on lifespan is mainly due to the attenuation of age-associated increase in oxidative stress [28]. Antioxidant properties of fullerene derivatives have also been examined in studies of hair loss. Patients suffering different conditions such as alopecia, chemotherapy, and reactions to various chemicals could benefit from these findings. Zhou et al. [29] reported that fullerene derivatives accelerated the hair growth in mice and human skin. In addition, these molecules significantly increase the number of hair follicles. Finally, the most recent paper on the treatment of liver injury with $\mathrm{C}_{60}$ derivative tells us that interest in fullerene application is still high [30].

5.2. Antitumour and Antimetastatic Agent. Modulation of oxidative stress in tumour tissues, inhibition of the formation of angiogenesis factors, and subsequent reduction in tumour 
vessel density and the nutrient supply to tumour cells could be important mechanisms by which fullerenol $\mathrm{C}_{60}(\mathrm{OH})_{20}$ aggregates inhibit tumour growth and suppress carcinoma metastasis in vivo [31]. In the case against $\mathrm{KSHV}$-associated primary effusion lymphoma (PEL), seven water-soluble fullerene derivatives were investigated as potential drug candidates. It was discovered that pyrrolidinium fullerene derivative, $1,1,1^{\prime}, 1^{\prime}$-tetramethyl [60]fullerenodipyrrolidinium diiodide, induced apoptosis of PEL cells. Pyrrolidinium fullerene treatment significantly reduced the viability of PEL cells compared with KSHV-uninfected lymphoma cells and induced the apoptosis of PEL cells by activating caspase- 9 via procaspase9 cleavage [32]. The results of $\mathrm{Hu}$ et al. suggested that folacin $\mathrm{C}_{60}$ derivative has the potential to prevent oxidative stressinduced cell death without evident toxicity. The folacin $\mathrm{C}_{60}$ derivative self-assembled to form spherical aggregates in water. Because the compound was amphiphilic, it could penetrate the cell membrane and protect PC12 cells against hydrogen peroxide-induced cytotoxicity [33,34]. Methanofullerene derivative [60] bearing four carboxylic groups, whose sodium and potassium salts are water soluble, is compound that has been confirmed to possess antiviral and anticancer activity as well as pronounced antioxidant properties in combination with a low toxicity. The anticancer activity was assessed on murine leukemia P388 tumour-bearing mice. Antiviral activity of 1-Na was investigated against HIV-1 and HIV-2 and showed comparable activity against both virus strains [35].

5.3. Photosensitizers and Sonosensitizers. Photodynamic therapy (PDT) is light-based therapy which is a nonsurgical procedure, with minimally invasive approach that has been used in the treatment of many solid cancers as well as other diseases [36]. PDT requires the simultaneous presence of a photosensitizer, oxygen, and light. Fullerenes possess some of the advantages in comparison to the other types of photosensitizers: (1) they are comparatively more photostable and demonstrate less photobleaching when compared with tetrapyrroles and synthetic dyes; (2) fullerenes show both kinds of photochemistry comprising free radicals and singlet oxygen while tetrapyrroles demonstrate largely singlet oxygen; (3) fullerenes can be chemically modified for tuning the drug's partition coefficient and $p K_{\mathrm{a}}$ values for the variation of in vivo lipophilicity and the prediction of their distribution in biological systems; (4) to enhance the overall quantum yield and the ROS production and to extend their absorption spectrum further into the red wavelengths, a light-harvesting antennae can be chemically attached to $\mathrm{C}_{60}$; (5) molecular self-assembly of fullerene cages into vesicles allow improved drug delivery and can produce self-assembled nanoparticles that may have different tissuetargeting properties [37]. Radical scavenging studies using the 1,1'-diphenyl-2-picrylhydrazyl radical showed that $\mathrm{C}_{60}$ in combination with human serum albumin $\left(\mathrm{C}_{60} / \mathrm{HSA}\right)$ had an increased antioxidant activity, compared to HSA alone. Further, $\mathrm{C}_{60} / \mathrm{HSA}$ efficiently generated not only superoxide anion radicals $\mathrm{O}_{2}{ }^{--}$but also singlet oxygen ${ }^{1} \mathrm{O}_{2}$ through photoirradiation. $\mathrm{C}_{60} / \mathrm{HSA}$ showed $\mathrm{A} 549$ cell toxicity characteristics after light irradiation, but no toxicity was observed in the absence of irradiation. In this way, $\mathrm{C}_{60} / \mathrm{HSA}$ not only has an excellent stability and antioxidant activity but also has considerable phototoxicity properties [38]. Ikeda et al. have investigated the cationic $\mathrm{C}_{60}$ derivative $\gamma$ - $\mathrm{CDx}$ complex and showed that it had higher photodynamic ability than pristine $\mathrm{C}_{60}$ because the complex possessed the ability to generate high levels of ${ }^{1} \mathrm{O}_{2}$ and provided a higher level of intracellular uptake. The photodynamic activity of this complex was also greater than photofrin, which is the most widely used clinical photosensitizer [39]. The other cationic derivative of $\mathrm{C}_{60}$ was examined in vivo by $\mathrm{Lu}$ et al. They used $\mathrm{C}_{60}$ functionalized with three dimethylpyrrolidinium groups $\left(\mathrm{BF}_{6}\right)$ which had been shown as highly active broad-spectrum antimicrobial photosensitizer in vitro when combined with white-light illumination. In the in vivo study, two mouse models of infected wounds, potentially lethal, were used. An excisional wound on the mouse back was contaminated with one of two stable bioluminescent Gram-negative species, Proteus mirabilis and Pseudomonas aeruginosa. A solution of $\mathrm{BF}_{6}$ was placed into the wound followed by delivery of up to $180 \mathrm{~J} / \mathrm{cm}^{2}$ of broadband white light (400$700 \mathrm{~nm}$ ). In both cases, there was a light-dose-dependent reduction of bioluminescence from the wound, not observed in control groups (light alone or $\mathrm{BF}_{6}$ alone). Fullerene-mediated photodynamic therapy of mice infected with $P$. mirabilis led to $82 \%$ survival compared with $8 \%$ survival without treatment. Photodynamic therapy of mice infected with highly virulent $P$. aeruginosa did not lead to survival, but when photodynamic therapy was combined with a suboptimal dose of the antibiotic tobramycin $(6 \mathrm{mg} / \mathrm{kg}$ for 1 day) there was a synergistic therapeutic effect with a survival of $60 \%$ compared with a survival of $20 \%$ with tobramycin alone [40].

Nanomaterials with multifunctional characteristics such as, for cancer diagnosis, PDT, radiofrequency, thermal therapy, and magnetic targeting applications have become more and more popular in nanomedicine. One such hybrid is the nanocomposite synthesized via decorating iron oxide nanoparticles (IONP) onto fullerene $\left(\mathrm{C}_{60}\right)$ and then functionalized by polyethylene glycol (PEG2000), giving $\mathrm{C}_{60}-\mathrm{IONP}-$ PEG excellent stability in physiological solutions. Hematoporphyrin monomethyl ether (HMME), a new photodynamic anticancer drug, was conjugated to $\mathrm{C}_{60}$-IONP-PEG, forming a $\mathrm{C}_{60}$-IONP-PEG/HMME drug delivery system, which showed an excellent magnetic targeting ability in cancer therapy. Compared with free HMME, remarkably enhanced photodynamic cancer cell killing effect using $\mathrm{C}_{60^{-}}$ IONP-PEG/HMME was realized not only in cultured B16-F10 cells in vitro but also in an in vivo murine tumour model due to 23-fold higher HMME uptake of tumour and strong photodynamic activity of $\mathrm{C}_{60}$-IONP-PEG [41]. In another study by Shi and coworkers, folic acid (FA), a widely used tumour targeting molecule, was linked to $\mathrm{C}_{60}$-IONP-PEG in order to obtain an active tumour targeting effect to MCF-7 cells and malignant tumour in mice models. $\mathrm{C}_{60}$-IONPPEG-FA served not only as a powerful tumour diagnostic 
magnetic resonance imaging contrast agent but also as a strong photosensitizer and powerful agent for photothermal ablation of tumour. Furthermore, a remarkable synergistic enhancement of PDT combination with thermal therapy was also observed during the treatment both in vitro and in vivo. Moreover, the multifunctional nanoplatform also could selectively kill cancer cells in highly localized regions via the excellent active tumour targeting and magnetic target abilities [42].

On the other hand, sonodynamic therapy is based on the sonosensitizing agent (sonosensitizer) and its subsequent activation by ultrasound irradiation. Yumita et al. have examined polyhydroxy fullerene (PHF) and the participation of lipid peroxidation in the mechanism of the sonodynamically induced antitumour effect. Sarcoma 180 cells were exposed to $2 \mathrm{MHz}$ ultrasound in the presence and the absence of PHF. Significant enhancement of the rates of both ultrasonically induced cell damage and lipid peroxidation was observed in the presence of PHF and was positively correlated with PHF. The enhancement of cell damage and lipid peroxidation with PHF was suppressed by reactive oxygen scavengers such as histidine and tryptophan [43].

5.4. Biosensors. A major problem for the application of biosensors is their reduction of performance caused by the inactivation of biomolecules. In order to solve this problem, antioxidant defense systems have been used to reduce the oxidative damage. In the study of Guo et al., polyhydroxylated fullerene derivatives $\left(\mathrm{C}_{60}(\mathrm{OH})_{x}\right)$ were introduced into hemoglobin $(\mathrm{Hb})$ electrochemical biosensors through layerby-layer assembly. Not only have $\mathrm{C}_{60}(\mathrm{OH})_{x}$ provided a favorable microenvironment to realize the direct electrochemistry and electrocatalysis of hemoglobin, but they have been successfully used as protective compounds to reduce the oxidant damage caused by the attack of $\mathrm{H}_{2} \mathrm{O}_{2}$ as well [44].

5.5. Bone Repair. Fracture healing involves complex processes of cell and tissue proliferation and differentiation. Many players are involved including growth factors, inflammatory cytokines, antioxidants, bone breakdown (osteoclast) and bone building (osteoblast) cells, hormones, amino acids, and various other nutrients. Traumatic injuries and pathological conditions, such as osteoporosis, osteonecrosis, and bone tumours, can lead to bone fractures that do not heal through endogenous mechanisms. Yang et al. have applied an innovative approach to solve the issue. They used fullerol as a strong antioxidant to enhance osteogenic differentiation in adipose-derived stem cells. When incubated together with osteogenic medium, fullerenol promoted osteogenic differentiation in a dose-dependent manner. It was also proved that fullerenol promoted expression of FoxO1, a major functional isoform of forkhead box $\mathrm{O}$ transcription factors that defend against reactive oxygen species in bone [45]. It was also shown that fullerenol can be potentially used for prevention and treatment of corticosteroid-induced osteonecrosis. Liu et al. evaluated the effect of fullerenol on adipogenic and osteogenic differentiation of a mouse bone marrow derived multipotent cell line, D1. Simultaneous treatment of dexamethasone with antioxidant glutathione or fullerenol decreased the number of cells containing lipid vesicles. Treatment with dexamethasone for 7 days resulted in a significant increase in adipogenic markers peroxisome proliferator-activated receptor gamma and adipocyte protein 2 gene expression. In addition, decrease in expression of osteogenic markers runtrelated transcription factor 2 and osteocalcin and antioxidative enzymes superoxide dismutase and catalase was also observed. While glutathione and fullerenol both were able to antagonize the effects of dexamethasone, fullerenol had a greater effect than glutathione. Cellular reactive oxygen species increased after dexamethasone treatment, and addition of fullerenol attenuated this activity which indicated that fullerenol inhibited adipogenesis and simultaneously enhanced osteogenesis by marrow mesenchymal stem cells [46].

5.6. Anti-Inflammatory Agents. Inflammation is a complex immunovascular response which involves immune cells, blood vessels, and molecular mediators with the purpose to eliminate the initial cause of cell injury, to clear out necrotic cells and tissues, and to initiate their reparation. Symptoms of inflammation are unpleasant and can include redness, swollen joint, joint pain, joint stiffness, and loss of joint function. In chronic inflammation or in autoimmune responses, the body's normally protective immune system causes damage to its own tissues and can lead to various diseases such as different types of arthritis, fibromyalgia, muscular low back pain, muscular neck pain, lupus erythematosus, and cancer. Liu et al. have investigated the anti-inflammatory effects of fullerol on mouse dorsal root ganglia (DRG) under TNF- $\alpha$ induction. Their results undoubtedly suggested that fullerol treatment suppresses the inflammatory responses of DRG and neurons, as well as cellular apoptosis, by decreasing the level of ROS and enhancing antioxidative enzyme gene expression [47]. In the study of Dragojevic-Simic et al., they have compared anti-inflammatory effects of FNP in regard to amifostine (AMI) and indomethacin (IND). FNP and IND, dissolved in dimethylsulfoxide, and AMI, dissolved in saline, were intraperitoneally injected to rats in a dose range of $12.5-75 \mathrm{mg} / \mathrm{kg}, 3-10 \mathrm{mg} / \mathrm{kg}$, and $50-300 \mathrm{mg} / \mathrm{kg}$, respectively. The carrageenan-induced rat footpad edema test was used for anti-inflammatory evaluation. The drugs were given 30 min before carrageenan injection. Footpad swelling was measured 3 hours after carrageenan application. FNP dose dependently and significantly reduced the extent of footpad edema, comparable to that of IND and significantly better than AMI. Histopathological examination confirmed these results [48].

Dexamethasone (DEX) is a well-known anti-inflammatory drug, whose widespread clinical use is restricted by its serious side effects. By conjugation of DEX with $\mathrm{C}_{60}$, Zhang and coworkers have found that DEX retained the anti-inflammatory activity while side effects were reduced. In mouse thymocytes, the cytotoxicity of $\mathrm{DEX}-\mathrm{C}_{60}$ was significantly lower than that of free DEX and much less 
apoptotic thymocytes were noticed. Interestingly, such reduction of cytotoxicity and apoptosis were not observed when equal moles of free $\mathrm{C}_{60}$ and free DEX were coincubated with thymocytes, suggesting that the conjugation alters the signal pathway of DEX. Researchers have also found that the binding of DEX-C 60 onto glucocorticoid receptor (GR) was partially blocked in the thymocytes, which resulted in downregulation of several apoptosis-related genes [49].

Tuftsin (Thr-Lys-Pro-Arg) is a naturally occurring tetrapeptide which possesses a wide range of biological activities, including stimulation of phagocytosis, motility, and chemotaxis of phagocytes, for example, neutrophils, monocytes, and macrophages. However, the degradation of the peptide in serum, especially caused by leucine aminopeptidase, greatly limits its clinical use [50]. To solve this problem, $\mathrm{Xu}$ et al. have come up with the idea to conjugate fullerene $\mathrm{C}_{60}$ to tuftsin by covalently linking with the carboxyl terminal and the amino terminal, respectively. The two compounds, $\mathrm{NH}_{2}$-etuftsine $\mathrm{C}_{60}$ and $\mathrm{C}_{60}$ etuftsine$\mathrm{COOH}$, were synthesized. The $\mathrm{C}_{60}$ etuftsin conjugates showed complete resistance to the leucine aminopeptidase degradation. At the same time, both of the conjugates showed more potent stimulation activities than the free tuftsin in the phagocytosis and chemotaxis of murine peritoneal macrophages. Moreover, they could upregulate significantly the MHC II molecule expression on the surface of macrophages, whereas the free tuftsin shows no such effect. Finally, both conjugates show no toxicity to macrophages [51].

Ischemic stroke can be the cause of brain inflammation. The brain's kinds of tissue become swollen and the patient could suffer headache and a fever, as well as more severe symptoms in some cases. Glucosamine $(\mathrm{GlcN})$, which attenuates cerebral inflammation after stroke, was combined with fullerenol into conjugates (GlcN-F) and their protective effects regarding stroke-induced cerebral inflammation and cellular damage were examined. Fullerene derivatives or vehicle was administered intravenously in normotensive WistarKyoto (WKY) rats and in spontaneously hypertensive rats (SHR) immediately after transient middle cerebral artery occlusion. Treated rats showed an amelioration of neurological symptoms as both fullerenol and GlcN-F prevented neuronal loss in the perilesional area. Cerebral immunoreactivity was reduced in treated WKY and SHR. Expression of IL$1 \beta$ and TLR- 4 was attenuated in fullerenol-treated WKY rats [52].

\section{Fullerenes: Misconception or Milestone of Medicine}

It is well established that fullerenes have wide spectrum of potential and promising applications in medicine. However, there are many debates about the health and safety issues that fullerenes may have in biological systems. Existing studies report inconclusive and conflicting results regarding the toxicity of fullerene nanoparticles [53]. The first study that reported oxidative damage in brain and gills of largemouth bass [54] later on was proven to be unfounded since it did not include adequate control and could not exclude the effects of impurities. However, the recent study has demonstrated that fullerenes may create risk to benthic organisms, particularly small agglomerates of fullerene [55]. Nakagawa et al. have revealed that $\mathrm{C}_{60}(\mathrm{OH})_{24}$ induced DNA fragmentation in rat hepatocytes, which could be prevented with special pretreatment [56]. Furthermore, study that investigated cytotoxic effects of fullerenol in different cell types concluded that cytotoxicity was cell type specific and that cell cycle was arrested in G1 phase [57]. Saathoff et al. have observed decrease in viability of human epidermal keratinocytes only when treated with the highest concentration of $\mathrm{C}_{60}(\mathrm{OH})_{32}$ (used range was $0.000544-42.5 \mu \mathrm{g} / \mathrm{mL}$, used fullerenols were $\mathrm{C}_{60}(\mathrm{OH})_{20}$, $\mathrm{C}_{60}(\mathrm{OH})_{24}$, and $\left.\mathrm{C}_{60}(\mathrm{OH})_{32}\right)$ [58]. Surface chemistry and concentration of fullerene nanoparticles, as well as the cell type, are the major factors involved in fullerene toxicity. Development of high-throughput analysis, particularly highcontent screening, will enable the generation of toxicological data contributing to the safety assessment of fullerene and its derivatives in biological systems. This will contribute to a better understanding of potentially hazardous effects in humans and the environment [59].

\section{Fullerenes and Immunity}

One of the main focal points is, undoubtedly, fullerenes' modulation of possible immune responses. However, a large body of evidence on their influence on immune system is still missing. Previous study by Chen et al. revealed that $\mathrm{C}_{60}$ fullerene derivative, conjugated to bovine thyroglobulin, induced production of fullerene-specific IgG antibodies in immunized mice [60], demonstrating an ability of adaptive arm of immune system to recognize novel chemical species that were encountered. Similar observation was made by Braden et al. who reported IgG antibodies specific to fullerene when it was conjugated to the carrier protein, rabbit serum albumin (RSA) (Figure 1) [61]. The humoral immune response protects the extracellular space, and during initial infection, the adaptive immune system is slow to start but rapidly excludes the invader when the organism is rechallenged with the same pathogen. However, it remains unclear whether it is generation of specific antibodies response of immune system to the fullerene nanoparticle itself or it is response to the conjugate with the carrier proteins. In the case of the latter, it is possibly due to the increase in size of nanoparticle [62].

The first study to investigate interaction between $\mathrm{C}_{60}$ carboxyfullerene and cells of immune system revealed that $\mathrm{C}_{60}$ was able to protect human peripheral blood mononuclear cells (PBMCs) from apoptosis, due to a mechanism that implicated mitochondrial membrane potential integrity [63]. Recent study by Bunz et al. has demonstrated that neither polyhydroxy- $\mathrm{C}_{60}$ (poly- $\mathrm{C}_{60}$ ) nor N-ethyl-polyamino$\mathrm{C}_{60}$ (nepo- $\mathrm{C}_{60}$ ) nanoparticles were able to alert adaptive immunity, since they have had no influence on $\mathrm{T}$ cell reactivity (no T cell proliferation was observed as well as no increase in $\mathrm{T}$ cell cytokine production was noticed) when PBMCs were treated with these nanoparticles. However, significant 


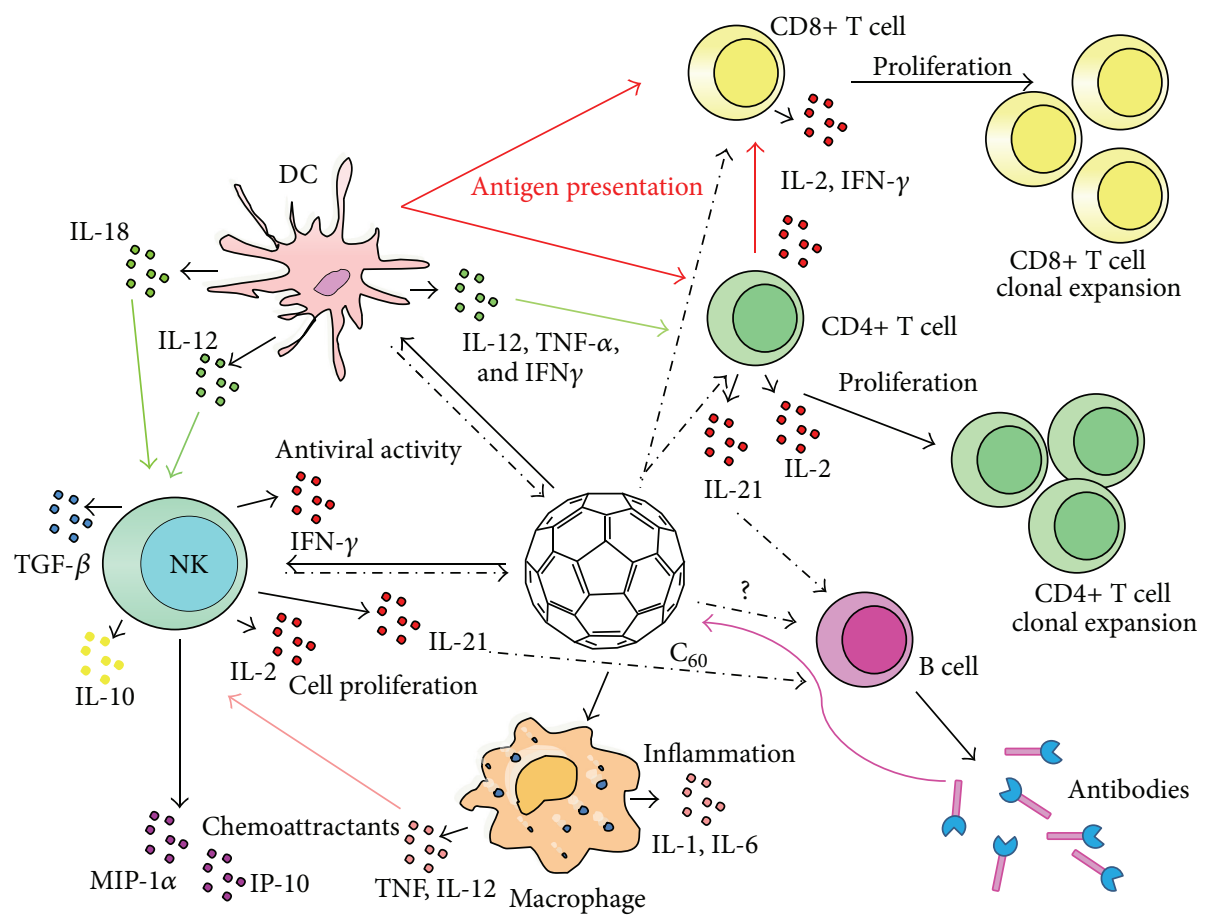

FIGURE 1: Response of the cells of innate and adaptive immune system to fullerene. The cells of the innate immune system are the first to respond. When they encounter the intruder, they become activated and start producing different cytokines, which have direct antiviral activity (IFN- $\gamma$, TNF- $\alpha$ ), deliver stimulatory signals to other cells of the innate system (IL-12, IL-18), initiate inflammation (IL-1 $\alpha / \beta$, IL-6), or act as chemoattractants that recruit inflammatory cells to the site of infection (MIP-1 $\alpha$, IP-10). During this cascade of events, the antigens are presented to T cells, mainly by DC, which are the professional antigen presenting cells that link the innate and adaptive immune system. When primed, T cells secrete IL-2, which induces their clonal proliferation and development of effector functions. Differentiated effector cells, particularly CD8+ T cells, tackle infection and eliminate the virus. B cells can be activated by cells of innate immunity (IL-21) or directly by antigens, and upon activation they differentiate into plasma cells producing antigen specific antibodies.

increase in production of IL-6 and propagation of CD56+ cells (natural killer cells) indicated that these fullerenes have activated the part of PBMCs that belongs to the innate immunity [64]. Innate arm of the immune system is a part of universal host defense mechanism, present in plants and animals, with molecular modules having probably evolved before the division into these two kingdoms [65]. In humans, when the first line of defense, represented by the physical barrier of skin and mucosa, is compromised, an antigen nonspecific response against the pathogen is delivered by the innate immune system. This system is initiated within a few minutes following the beginning of infection. The innate immune system is composed of many serum proteins (including acute phase proteins and cytokines) and cells, with phagocytes (macrophages, neutrophils, and dendritic cells (DC)) and natural killer (NK) cells being essential for functioning of the system (Figure 1) [66].

Liu et al. have demonstrated, in a murine $\mathrm{H} 22$ hepatoma model, that fullerene derivatives $\left(\mathrm{Gd} @ \mathrm{C}_{82}(\mathrm{OH})_{22}\right)$ were able to activate $\mathrm{T}$ lymphocyte and to increase the ratio of CD4+/CD8+ T cells, improving anticancer activity. In addition, they have showed an enhanced production of cytokine TNF-alpha by macrophages confirming the induction of complete immune response, both innate and adaptive, and reducing a tumour neoformation in this model by around
$60 \%$ [67]. Furthermore, the same group has demonstrated that water-soluble fullerenol $\mathrm{C}_{60}(\mathrm{OH})_{20}$ nanoparticles have immunomodulatory ability on both $\mathrm{T}$ cells and macrophages (Figure 1). These nanoparticles increased the Th1 response (IL-2, IFN-gamma, and TNF-alpha), decreased Th2 response (IL-4, IL-5, and IL-6), and were able to increase the production of TNF-alpha by $\mathrm{T}$ cells and macrophages almost threefold [68]. Previous study by $\mathrm{Zhu}$ et al. has also revealed fullerenol $\mathrm{C}_{60}(\mathrm{OH})_{x}$ immunomodulatory activity on macrophages, whose activation busted the innate immunity and therefore considerably inhibited the enlargement of murine $\mathrm{H} 22$ hepatocarcinoma [69].

Interaction between dendritic cells (DC) and natural killer (NK) cells may be crucial in shaping the innate response. Namely, DCs activate NK cells via production of IL12 and IL-18 or via expression of NK-activating ligands [70]. In addition, DCs are the most important antigen presenting cells (APC), whose main function is to ingest, process, and present antigen to $\mathrm{T}$ cells, having a crucial role in networking the innate and adaptive immune responses. Influence of fullerenes on DC has also been reported (Figure 1). In mouse model, gado fullerenol $\left(\mathrm{Gd} @ \mathrm{C}_{82}(\mathrm{OH})_{22}\right)(\mathrm{n})$ nanoparticles induced maturation and activation of $\mathrm{DC}$ as well as enhancement of Th1 immune response (IFN-gamma), thus providing understanding for great antitumour activity 
of $\left(\mathrm{Gd} @ \mathrm{C}_{82}(\mathrm{OH})_{22}\right)(\mathrm{n})$ nanoparticles [71]. Interestingly, a recent study has shown that the same gado fullerenol nanoparticle could disturb and block proline-rich motif from binding to $\mathrm{SH} 3$ domain, which are rather common in protein-protein interaction, frequently used during the establishment of immune or cellular regulatory responses [72]. Previously, the same group has published observation that this nanoparticle significantly reduces activity of matrix metalloproteinases-9 (MMP-9) which contributes to inhibition of neoplastic growth in human pancreatic cancer grafts in a nude mouse model. Since MMPs are known to participate in angiogenesis and variety of immune interactions, it is expected that suppression of MMP activity will result in decline of tumour survival and invasion [73].

A gene microarray analysis on zebrafish embryos, microinjected with a sublethal dose of hydroxylated fullerenes $\left(\mathrm{C}_{60}(\mathrm{OH})_{24}\right)$, demonstrated significant change in expression of different genes involved in immune response [74]. The same group, using another fish model (Pimephales promelas) and using quantitative PCR, has confirmed that hydroxylated fullerenes caused changes at the mRNA levels of highly conserved genes involved in innate immunity [75]. A recent computational study has shown that $\mathrm{C}_{60}$ fullerenes can act as ligands for toll-like receptors (TLRs) and therefore can be recognized as pathogens, inducing proinflammatory immune response (IL-8, MCP-1) [76]. Additionally, strong splenic inflammation with increased production of IL-2 and TNF-alpha was observed in mice spleen tissue [77]. However, some studies emphasized strong anti-inflammatory responses of fullerene $\mathrm{C}_{60}$. In adjuvant-induced arthritis in rats [78], $\mathrm{C}_{60}$ decreased neutrophil phagocytic activity and production of antinuclear antibodies, resulting in inflammation decline, and also facilitated in restitution of spleen morphology. Furthermore, inorganic fullerene-like nanoparticles (molybdenum disulfide nanoparticles) significantly decreased proinflammatory immune response (IL-lbeta, IL6 , IL-8, and TNF-alpha) in nontransformed human bronchial cells [79].

A very challenging area in immunology is, certainly, vaccine development. A novel approach to combat infectious diseases is evolution of nanovaccines, which will be able to cure and prevent diseases better than currently used vaccines. Explicitly, nanoparticles are used to deliver components to which is desired a specific immune response, to increase adjuvant activity and to enhance antigenicity of the vaccine components [62]. A recent study by Xu et al. has proved that fullerenol nanoparticles can act as virus-like particles and can be used as the dual-functional nanoadjuvant for HIV DNA vaccine. Namely, they have proved that this vaccine design enables innate immune response via activation of multiple TLRs and their signaling pathways, resulting in decrease of antigen dosage and frequency in immunization, while keeping immunity levels capable of battling the HIV infection at an early stage [80]. Hence, fullerenol nanovaccine was able to trigger desirable immune response and to enhance targeting of specific components of immune system.

Since nanovaccines have a great potential in site-specific delivery of antigens, improved bioavailability of antigen components, and a reduced side effect profile [81], they may have a major role in the vaccine design in the future. This is incredibly important, specially for the infections with currently no available vaccines, which are global health burden, such as hepatitis C or HIV, distributed worldwide with a number of infected individuals constantly rising.

\section{Conclusion}

This review represents an overview of the most relevant publications on fullerene $\mathrm{C}_{60}$ and its derivatives applications, with the anti/prooxidative features being a central to the topic. Antioxidative properties are implied in majority of observed phenomena caused by fullerenes (radiation-induced injury protection, neuroprotection, anti-inflammatory agent, drug and gene delivery, antitumour therapy, adjuvant within different treatments, and bone reparation). However, prooxidative characteristics were utilized in photodynamic and sonodynamic treatments. Furthermore, fullerenes have potential to modulate immune cells function leading to effects on cytokine production, in order to create the cytokine milieu that is favourable for appropriate immune response. This feature is explored for vaccine design, but full understanding of fullerene nanoparticle and immune system interactions are to be further elucidated. Nevertheless, this promising strategy in vaccine development is exceptionally valuable in rapid discovery of new vaccines, as potential tools for therapeutic and prophylactic purposes.

\section{Conflict of Interests}

The authors declare that there is no conflict of interests regarding the publication of this paper.

\section{Acknowledgment}

This study was supported by a grant from the Ministry of Education, Science and Technological Development of the Republic of Serbia, Grant no. III45005, "Functional, functionalized and accomplished nanomaterials."

\section{References}

[1] P. J. Krusic, E. Wasserman, P. N. Keizer, J. R. Morton, and K. F. Preston, "Radical reactions of $\mathrm{C}_{60}$," Science, vol. 254, no. 5035, pp. 1183-1185, 1991.

[2] J. W. Arbogast, A. P. Darmanyan, C. S. Foote et al., "Photophysical properties of sixty atom carbon molecule (C60)," Journal of Physical Chemistry, vol. 95, no. 1, pp. 11-12, 1991.

[3] J. P. Kamat, T. P. A. Devasagayam, K. I. Priyadarsini, and H. Mohan, "Reactive oxygen species mediated membrane damage induced by fullerene derivatives and its possible biological implications," Toxicology, vol. 155, no. 1-3, pp. 55-61, 2000.

[4] C. M. Sayes, J. D. Fortner, W. Guo et al., "The differential cytotoxicity of water-soluble fullerenes," Nano Letters, vol. 4, no. 10, pp. 1881-1887, 2004.

[5] C. M. Sayes, A. M. Gobin, K. D. Ausman, J. Mendez, J. L. West, and V. L. Colvin, "Nano-C60 cytotoxicity is due to lipid peroxidation," Biomaterials, vol. 26, no. 36, pp. 7587-7595, 2005. 
[6] H. J. Johnston, G. R. Hutchison, F. M. Christensen, K. Aschberger, and V. Stone, "The biological mechanisms and physicochemical characteristics responsible for driving fullerene toxicity," Toxicological Sciences, vol. 114, no. 2, pp. 162-182, 2009.

[7] K. Stankov, I. Borisev, V. Kojic, L. Rutonjski, G. Bogdanovic, and A. Djordjevic, "Modification of antioxidative and antiapoptotic genes expression in irradiated $\mathrm{K} 562$ cells upon fullerenol $\mathrm{C}_{60}(\mathrm{OH})_{24}$ nanoparticle treatment," Journal of Nanoscience and Nanotechnology, vol. 13, no. 1, pp. 105-113, 2013.

[8] J. Cadet, T. Douki, J.-L. Ravanat, and P. Di Mascio, "Sensitized formation of oxidatively generated damage to cellular DNA by UVA radiation," Photochemical \& Photobiological Sciences, vol. 8, no. 7, pp. 903-911, 2009.

[9] J. Cadet, T. Douki, and J.-L. Ravanat, "Oxidatively generated damage to the guanine moiety of DNA: mechanistic aspects and formation in cells," Accounts of Chemical Research, vol. 41, no. 8, pp. 1075-1083, 2008.

[10] M. Y. Eropkin, E. Y. Melenevskaya, K. V. Nasonova et al., "Synthesis and biological activity of fullerenols with various contents of hydroxyl groups," Pharmaceutical Chemistry Journal, vol. 47, no. 2, pp. 87-91, 2013.

[11] S. Kato, R. Kikuchi, H. Aoshima, Y. Saitoh, and N. Miwa, "Defensive effects of fullerene- $\mathrm{C}_{60}$ /liposome complex against UVA-induced intracellular reactive oxygen species generation and cell death in human skin keratinocytes HaCaT, associated with intracellular uptake and extracellular excretion of fullerene- $\mathrm{C}_{60}$," Journal of Photochemistry and Photobiology B: Biology, vol. 98, no. 2, pp. 144-151, 2010.

[12] S. Kato, H. Aoshima, Y. Saitoh, and N. Miwa, "FullereneC60/liposome complex: defensive effects against UVA-induced damages in skin structure, nucleus and collagen type I/IV fibrils, and the permeability into human skin tissue," Journal of Photochemistry and Photobiology B: Biology, vol. 98, no. 1, pp. 99-105, 2010.

[13] B. Halliwell, "Reactive oxygen species and the central nervous system," Journal of Neurochemistry, vol. 59, no. 5, pp. 1609-1623, 1992.

[14] W. H. Xiao and G. J. Bennett, "Effects of mitochondrial poisons on the neuropathic pain produced by the chemotherapeutic agents, paclitaxel and oxaliplatin," Pain, vol. 153, no. 3, pp. 704709, 2012.

[15] M. Ehrich, R. Van Tassell, Y. Li, Z. Zhou, and C. L. Kepley, "Fullerene antioxidants decrease organophosphate-induced acetylcholinesterase inhibition in vitro," Toxicology in Vitro, vol. 25, no. 1, pp. 301-307, 2011.

[16] G. Giordano, Z. Afsharinejad, T. Kavanagh, and L. Costa, "Reactive oxygen species mediate the neurotoxicity induced by organophosphorus insecticides in mouse cerebellar granule cells," Toxicological Sciences, vol. 90, p. 301, 2006.

[17] J. Tong, M. C. Zimmerman, S. Li et al., "Neuronal uptake and intracellular superoxide scavenging of a fullerene $\left(\mathrm{C}_{60}\right)$-poly $(2$ oxazoline)s nanoformulation," Biomaterials, vol. 32, no. 14, pp. 3654-3665, 2011.

[18] V. Vorobyov, V. Kaptsov, R. Gordon, E. Makarova, I. Podolski, and F. Sengpiel, "Neuroprotective effects of hydrated fullerene c60: cortical and hippocampal EEG interplay in an amyloidinfused rat model of Alzheimer's disease," Journal of Alzheimer's Disease, vol. 45, pp. 217-233, 2015.

[19] C.-M. Lee, S.-T. Huang, S.-H. Huang et al., "C60 fullerenepentoxifylline dyad nanoparticles enhance autophagy to avoid cytotoxic effects caused by the $\beta$-amyloid peptide,"
Nanomedicine: Nanotechnology, Biology, and Medicine, vol. 7, no. 1, pp. 107-114, 2011.

[20] T. Opitz, P. Richter, A. J. Carter, A. P. Kozikowski, H. Shinozaki, and K. G. Reymann, "Metabotropic glutamate receptor subtypes differentially influence neuronal recovery from in vitro hypoxia/hypoglycemia in rat hippocampal slices," Neuroscience, vol. 68, no. 4, pp. 989-1001, 1995.

[21] D. Giust, T. Da Ros, M. Martín, and J. L. Albasanz, "[60]Fullerene derivative modulates adenosine and metabotropic glutamate receptors gene expression: a possible protective effect against hypoxia," Journal of Nanobiotechnology, vol. 12, no. 1, article 27, 2014.

[22] H. Tsumoto, S. Kawahara, Y. Fujisawa et al., "Syntheses of watersoluble [60]fullerene derivatives and their enhancing effect on neurite outgrowth in NGF-treated PC12 cells," Bioorganic and Medicinal Chemistry Letters, vol. 20, no. 6, pp. 1948-1952, 2010.

[23] H. Zhang, L. Hou, X. Jiao, Y. Ji, X. Zhu, and Z. Zhang, "Transferrin-mediated fullerenes nanoparticles as $\mathrm{Fe}^{2+}$. dependent drug vehicles for synergistic anti-tumor efficacy," Biomaterials, vol. 37, pp. 353-366, 2015.

[24] M. Slavić, A. Djordjevic, R. Radojičić et al., "Fullerenol $\mathrm{C}_{60}(\mathrm{OH})_{24}$ nanoparticles decrease relaxing effects of dimethyl sulfoxide on rat uterus spontaneous contraction," Journal of Nanoparticle Research, vol. 15, no. 5, pp. 1650-1658, 2013.

[25] B. U. Srdjenovic, M. N. Slavić, K. M. Stankov et al., "Size distribution of fullerenol nanoparticles in cell culture medium and their influence on antioxidative enzymes in Chinese hamster ovary cells," Hemijska industrija, 2014.

[26] C.-C. Zhuge, J.-Y. Xu, J. Zhang et al., "Fullerenol protects retinal pigment epithelial cells from oxidative stress-induced premature senescence via activating SIRT1," Investigative Ophthalmology and Visual Science, vol. 55, no. 7, pp. 4628-4638, 2014.

[27] R. Bal, G. Türk, M. Tuzcu et al., "Protective effects of nanostructures of hydrated $\mathrm{C}_{60}$ fullerene on reproductive function in streptozotocin-diabetic male rats," Toxicology, vol. 282, no. 3, pp. 69-81, 2011.

[28] T. Baati, F. Bourasset, N. Gharbi et al., "The prolongation of the lifespan of rats by repeated oral administration of [60]fullerene," Biomaterials, vol. 33, pp. 4936-4946, 2012.

[29] Z. Zhou, R. Lenk, A. Dellinger et al., "Fullerene nanomaterials potentiate hair growth," Nanomedicine Nanotechnology, Biology, and Medicine, vol. 5, no. 2, pp. 202-207, 2009.

[30] Y. Umezaki, D. Iohara, M. Anraku et al., "Preparation of hydrophilic $\mathrm{C}_{60}(\mathrm{OH})_{10} / 2$-hydroxypropyl- $\beta$-cyclodextrin nanoparticles for the treatment of a liver injury induced by anoverdose of acetaminophen," Biomaterials, vol. 45, pp. 115-123, 2015.

[31] F. Jiao, Y. Liu, Y. Qu et al., "Studies on anti-tumor and antimetastatic activities of fullerenol in a mouse breast cancer model," Carbon, vol. 48, no. 8, pp. 2231-2243, 2010.

[32] T. Watanabe, S. Nakamura, T. Ono et al., "Pyrrolidinium fullerene induces apoptosis by activation of procaspase-9 via suppression of Akt in primary effusion lymphoma," Biochemical and Biophysical Research Communications, vol. 451, no. 1, pp. 93-100, 2014.

[33] Z. Hu, W. Guan, W. Wang, Z. Zhu, and Y. Wang, "Folacin $\mathrm{C}_{60}$ derivative exerts a protective activity against oxidative stressinduced apoptosis in rat pheochromocytoma cells," Bioorganic and Medicinal Chemistry Letters, vol. 20, no. 14, pp. 4159-4162, 2010.

[34] Z. Hu, Y. Huang, W. Guan, J. Zhang, F. Wang, and L. Zhao, "The protective activities of water-soluble C60 derivatives against 
nitric oxide-induced cytotoxicity in rat pheochromocytoma cells," Biomaterials, vol. 31, no. 34, pp. 8872-8881, 2010.

[35] A. B. Kornev, A. S. Peregudov, V. M. Martynenko et al., "Synthesis and biological activity of a novel water-soluble methano[60]fullerene tetracarboxylic derivative," Mendeleev Communications, vol. 23, no. 6, pp. 323-325, 2013.

[36] M. R. Hamblin and P. Mroz, Advances in Photodynamic Therapy: Basic, Translational, and Clinical, Artech House, 2008.

[37] S. K. Sharma, L. Y. Chiang, and M. R. Hamblin, "Photodynamic therapy with fullerenes in vivo: reality or a dream?" Nanomedicine, vol. 6, no. 10, pp. 1813-1825, 2011.

[38] A. Abdulmalik, A. Hibah, B. M. Zainy et al., "Preparation of soluble stable C60/human serum albumin nanoparticles via cyclodextrin complexation and their reactive oxygen production characteristics," Life Sciences, vol. 93, no. 7, pp. 277-282, 2013.

[39] A. Ikeda, T. Iizuka, N. Maekubo et al., "Cyclodextrin complexed [60]fullerene derivatives with high levels of photodynamic activity by long wavelength excitation," ACS Medicinal Chemistry Letters, vol. 4, no. 8, pp. 752-756, 2013.

[40] Z. Lu, T. Dai, L. Huang et al., "Photodynamic therapy with a cationic functionalized fullerene rescues mice from fatal wound infections," Nanomedicine, vol. 5, no. 10, pp. 1525-1533, 2010.

[41] J. Shi, X. Yu, L. Wang et al., "PEGylated fullerene/iron oxide nanocomposites for photodynamic therapy, targeted drug delivery and MR imaging," Biomaterials, vol. 34, no. 37, pp. 9666-9677, 2013.

[42] J. Shi, L. Wang, J. Gao et al., "A fullerene-based multi-functional nanoplatform for cancer theranostic applications," Biomaterials, vol. 35, no. 22, pp. 5771-5784, 2014.

[43] N. Yumita, Y. Iwase, T. Watanabe et al., "Involvement of reactive oxygen species in the enhancement of membrane lipid peroxidation by sonodynamic therapy with functionalized fullerenes," Anticancer Research, vol. 34, no. 11, pp. 6481-6487, 2014.

[44] X. Guo, S. Yang, R. Cui et al., "Application of polyhydroxylated fullerene derivatives in hemoglobin biosensors with enhanced antioxidant capacity," Electrochemistry Communications, vol. 20, no. 1, pp. 44-47, 2012.

[45] X. L. Yang, C. J. Li, Y. P. Wan, P. Smith, G. W. Shang, and Q. Cui, "Antioxidative fullerol promotes osteogenesis of human adipose-derived stem cells," International Journal of Nanomedicine, vol. 9, no. 1, pp. 4023-4031, 2014.

[46] H. Liu, X. Yang, Y. Zhang, A. Dighe, X. Li, and Q. Cui, "Fullerol antagonizes dexamethasone-induced oxidative stress and adipogenesis while enhancing osteogenesis in a cloned bone marrow mesenchymal stem cell," Journal of Orthopaedic Research, vol. 30, no. 7, pp. 1051-1057, 2012.

[47] Q. Liu, L. Jin, B. H. Mahon, M. D. Chordia, F. H. Shen, and X. Li, "Novel treatment of neuroinflammation against low back pain by soluble fullerol nanoparticles," Spine, vol. 38, no. 17, pp. 14431451, 2013.

[48] V. Dragojevic-Simic, V. Jacevic, S. Dobric et al., "Antiinflammatory activity of fullerenol $\mathrm{C}_{60}(\mathrm{OH})_{24}$ nano-particles in a model of acute inflammation in rats," Digest Journal of Nanomaterials and Biostructures, vol. 6, no. 2, pp. 819-827, 2011.

[49] Y. Zhang, L. Wang, Y. Sun et al., "Conjugation of dexamethasone to C60 for the design of an anti-inflammatory nanomedicine with reduced cellular apoptosis," ACS Applied Materials and Interfaces, vol. 5, no. 11, pp. 5291-5297, 2013.
[50] I. Z. Siemion and A. Kluczyk, "Tuftsin: on the 30-year anniversary of Victor Najjar's discovery," Peptides, vol. 20, no. 5, pp. 645-674, 1999.

[51] Y. Xu, J. Zhu, K. Xiang et al., "Synthesis and immunomodulatory activity of [60]fullerene-tuftsin conjugates," Biomaterials, vol. 32, no. 36, pp. 9940-9949, 2011.

[52] F. Fluri, D. Grünstein, E. Cam et al., "Fullerenols and glucosamine fullerenes reduce infarct volume and cerebral inflammation after ischemic stroke in normotensive and hypertensive rats," Experimental Neurology, vol. 265, pp. 142-151, 2015.

[53] C. Kepley, "Fullerenes in medicine; will it ever occur?" Journal of Nanomedicine \& Nanotechnology, vol. 3, no. 6, p. 1, 2012.

[54] E. Oberdörster, "Manufactured nanomaterials (fullerenes, C60) induce oxidative stress in the brain of juvenile largemouth bass," Environmental Health Perspectives, vol. 112, no. 10, pp. 10581062, 2004.

[55] G. C. Waissi-Leinonen, I. Nybom, K. Pakarinen, J. Akkanen, M. T. Leppänen, and J. V. Kukkonen, "Fullerenes $\left(\mathrm{nC}_{60}\right)$ affect the growth and development of the sediment-dwelling invertebrate Chironomus riparius larvae," Environmental Pollution, vol. 206, pp. 17-23, 2015.

[56] Y. Nakagawa, A. Inomata, A. Ogata, and D. Nakae, "Comparative effects of sulfhydryl compounds on target organellae, nuclei and mitochondria, of hydroxylated fullerene-induced cytotoxicity in isolated rat hepatocytes," Journal of Applied Toxicology, 2015.

[57] Y. Su, J.-Y. Xu, P. Shen et al., "Cellular uptake and cytotoxic evaluation of fullerenol in different cell lines," Toxicology, vol. 269, no. 2-3, pp. 155-159, 2010.

[58] J. G. Saathoff, A. O. Inman, X. R. Xia, J. E. Riviere, and N. A. Monteiro-Riviere, "In vitro toxicity assessment of three hydroxylated fullerenes in human skin cells," Toxicology in Vitro, vol. 25, no. 8, pp. 2105-2112, 2011.

[59] A. E. Nel, E. Nasser, H. Godwin et al., "A multi-stakeholder perspective on the use of alternative test strategies for nanomaterial safety assessment," ACS Nano, vol. 7, no. 8, pp. 6422-6433, 2013.

[60] B.-X. Chen, S. R. Wilson, M. Das, D. J. Coughlin, and B. F. Erlanger, "Antigenicity of fullerenes: antibodies specific for fullerenes and their characteristics," Proceedings of the National Academy of Sciences of the United States of America, vol. 95, no. 18, pp. 10809-10813, 1998.

[61] B. C. Braden, F. A. Goldbaum, B.-X. Chen, A. N. Kirschner, S. R. Wilson, and B. F. Erlanger, "X-ray crystal structure of an antiBuckminsterfullerene antibody Fab fragment: biomolecular recognition of $\mathrm{C}_{60}$," Proceedings of the National Academy of Sciences of the United States of America, vol. 97, no. 22, pp. 1219312197, 2000.

[62] B. S. Zolnik, Á. González-Fernández, N. Sadrieh, and M. A. Dobrovolskaia, "Minireview: nanoparticles and the immune system," Endocrinology, vol. 151, no. 2, pp. 458-465, 2010.

[63] D. Monti, L. Moretti, S. Salvioli et al., "C60 carboxyfullerene exerts a protective activity against oxidative stress-induced apoptosis in human peripheral blood mononuclear cells," Biochemical and Biophysical Research Communications, vol. 277, no. 3, pp. 711-717, 2000.

[64] H. Bunz, S. Plankenhorn, and R. Klein, "Effect of buckminsterfullerenes on cells of the innate and adaptive immune system: an in vitro study with human peripheral blood mononuclear cells," International Journal of Nanomedicine, vol. 7, pp. 4571-4580, 2012. 
[65] J. A. Hoffmann, F. C. Kafatos, C. A. Janeway Jr., and R. A. B. Ezekowitz, "Phylogenetic perspectives in innate immunity," Science, vol. 284, no. 5418, pp. 1313-1318, 1999.

[66] C. A. Janeway Jr. and R. Medzhitov, "Innate immune recognition," Annual Review of Immunology, vol. 20, pp. 197-216, 2002.

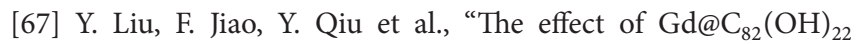
nanoparticles on the release of Th1/Th2 cytokines and induction of TNF- $\alpha$ mediated cellular immunity," Biomaterials, vol. 30, no. 23-24, pp. 3934-3945, 2009.

[68] Y. Liu, F. Jiao, Y. Qiu et al., "Immunostimulatory properties and enhanced TNF-alpha mediated cellular immunity for tumor therapy by $\mathrm{C}_{60}(\mathrm{OH})_{20}$ nanoparticles," Nanotechnology, vol. 20, no. 41, Article ID 415102, 2009.

[69] J. Zhu, Z. Ji, J. Wang et al., "Tumor-inhibitory effect and immunomodulatory activity of fullerol $\mathrm{C}_{60}(\mathrm{OH})_{x}$," Small, vol. 4, no. 8, pp. 1168-1175, 2008.

[70] T. Kanto and N. Hayashi, "Immunopathogenesis of hepatitis C virus infection: multifaceted strategies subverting innate and adaptive immunity," Internal Medicine, vol. 45, no. 4, pp. 183191, 2006

[71] D. Yang, Y. Zhao, H. Guo et al., “ $\left[\mathrm{Gd} @ \mathrm{C}_{82}(\mathrm{OH})_{22}\right]_{n}$ nanoparticles induce dendritic cell maturation and activate Thl immune responses," ACS Nano, vol. 4, no. 2, pp. 1178-1186, 2010.

[72] S.-G. Kang, T. Huynh, and R. Zhou, "Metallofullerenol $\mathrm{Gd} @ \mathrm{C}_{82}(\mathrm{OH})_{22}$ distracts the proline-rich-motif from putative binding on the SH3 domain," Nanoscale, vol. 5, no. 7, pp. 27032712, 2013.

[73] S.-G. Kang, G. Zhou, P. Yang et al., "Molecular mechanism of pancreatic tumor metastasis inhibition by $\mathrm{Gd} @ \mathrm{C}_{82}(\mathrm{OH})_{22}$ and its implication for de novo design of nanomedicine," Proceedings of the National Academy of Sciences of the United States of America, vol. 109, no. 38, pp. 15431-15436, 2012.

[74] B. Jovanović, T. Ji, and D. Palić, "Gene expression of zebrafish embryos exposed to titanium dioxide nanoparticles and hydroxylated fullerenes," Ecotoxicology and Environmental Safety, vol. 74, no. 6, pp. 1518-1525, 2011.

[75] B. Jovanović, L. Anastasova, E. W. Rowe, and D. Palić, "Hydroxylated fullerenes inhibit neutrophil function in fathead minnow (Pimephales promelas Rafinesque, 1820)," Aquatic Toxicology, vol. 101, no. 2, pp. 474-482, 2011.

[76] M. Turabekova, B. Rasulev, M. Theodore, J. Jackman, D. Leszczynska, and J. Leszczynski, "Immunotoxicity of nanoparticles: a computational study suggests that CNTs and $\mathrm{C}_{60}$ fullerenes might be recognized as pathogens by Toll-like receptors," Nanoscale, vol. 6, no. 7, pp. 3488-3495, 2014.

[77] N. Ding, N. Kunugita, T. Ichinose et al., "Intratracheal administration of fullerene nanoparticles activates splenic CD11b ${ }^{+}$cells," Journal of Hazardous Materials, vol. 194, pp. 324-330, 2011.

[78] L.É. Vesnina, T. V. Mamontova, M. V. Mikityuk et al., "Fullerene $\mathrm{C}_{60}$ exhibits immunomodulatory activity during adjuvantinduced arthritis in rats," Eksperimental'naya i Klinicheskaya Farmakologiya, vol. 75, no. 8, pp. 15-20, 2012.

[79] M. Pardo, T. Shuster-Meiseles, S. Levin-Zaidman, A. Rudich, and Y. Rudich, "Low cytotoxicity of inorganic nanotubes and fullerene-like nanostructures in human bronchial epithelial cells: relation to inflammatory gene induction and antioxidant response," Environmental Science \& Technology, vol. 48, no. 6, pp. 3457-3466, 2014.

[80] L. Xu, Y. Liu, Z. Chen et al., "Morphologically virus-like fullerenol nanoparticles act as the dual-functional nanoadjuvant for HIV-1 vaccine," Advanced Materials, vol. 25, no. 41, pp. 5928-5936, 2013.
[81] M. Zaman, M. F. Good, and I. Toth, "Nanovaccines and their mode of action," Methods, vol. 60, no. 3, pp. 226-231, 2013. 

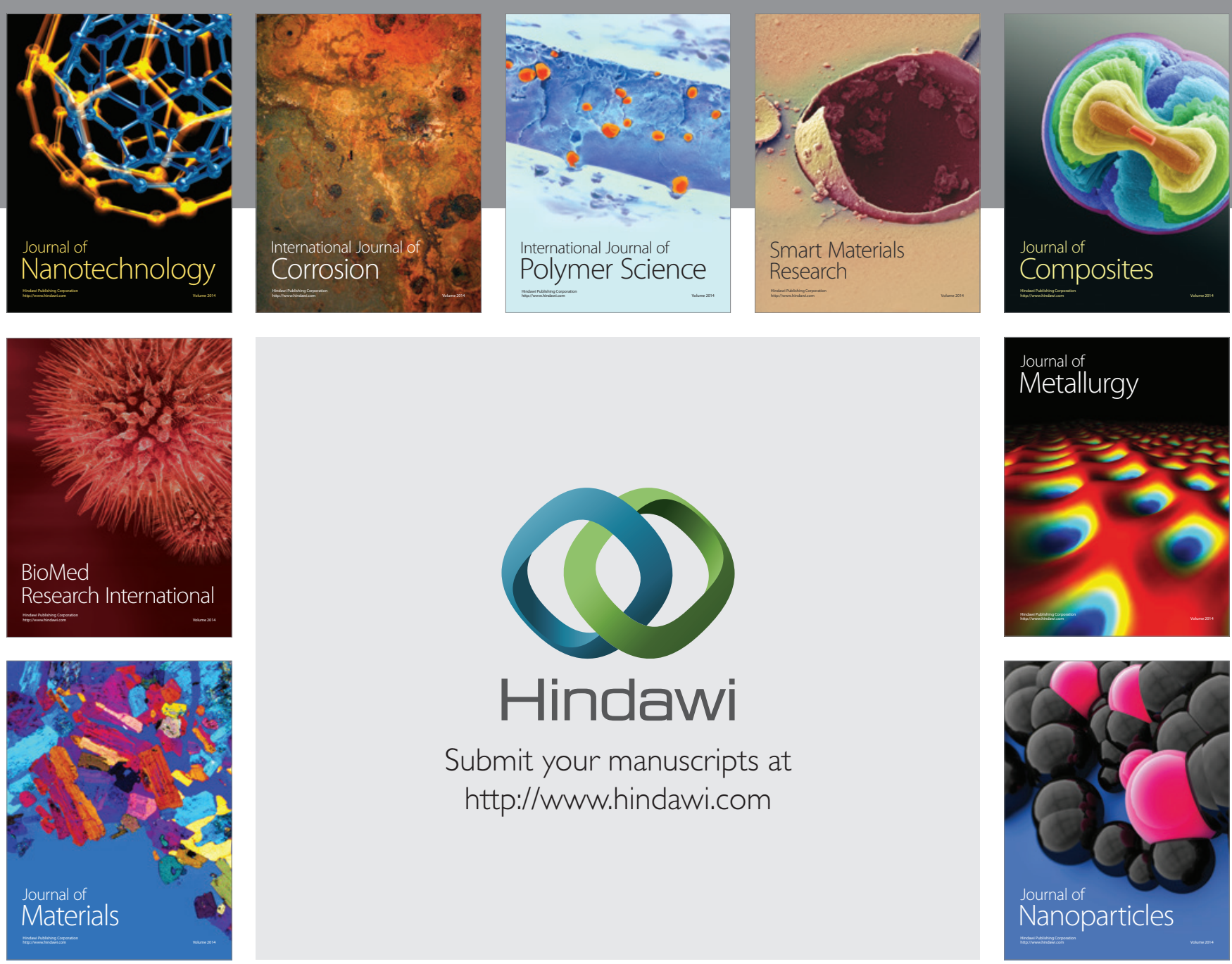

Submit your manuscripts at http://www.hindawi.com
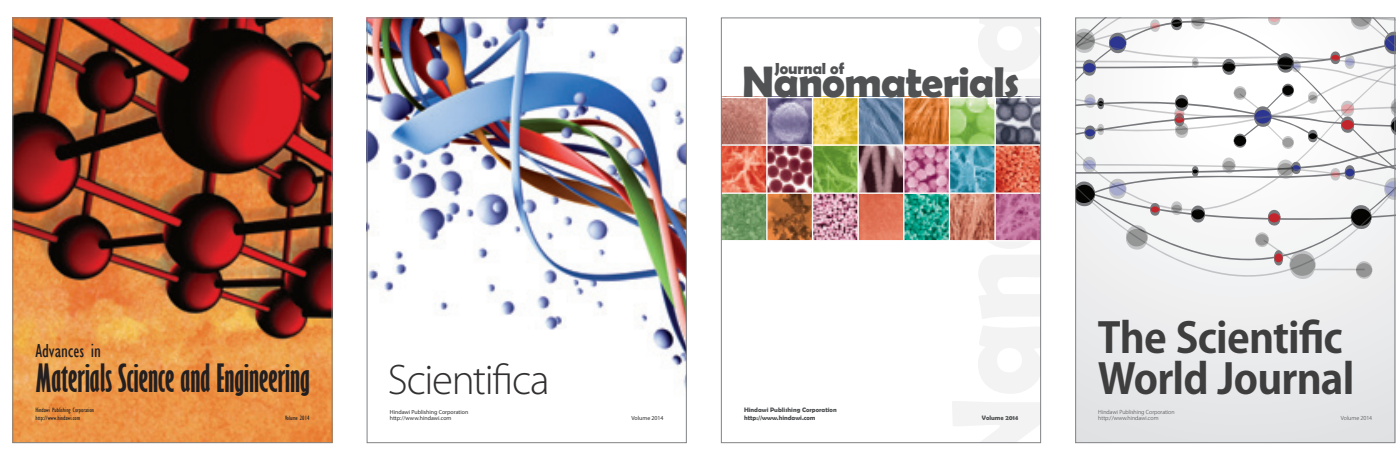

\section{The Scientific World Journal}
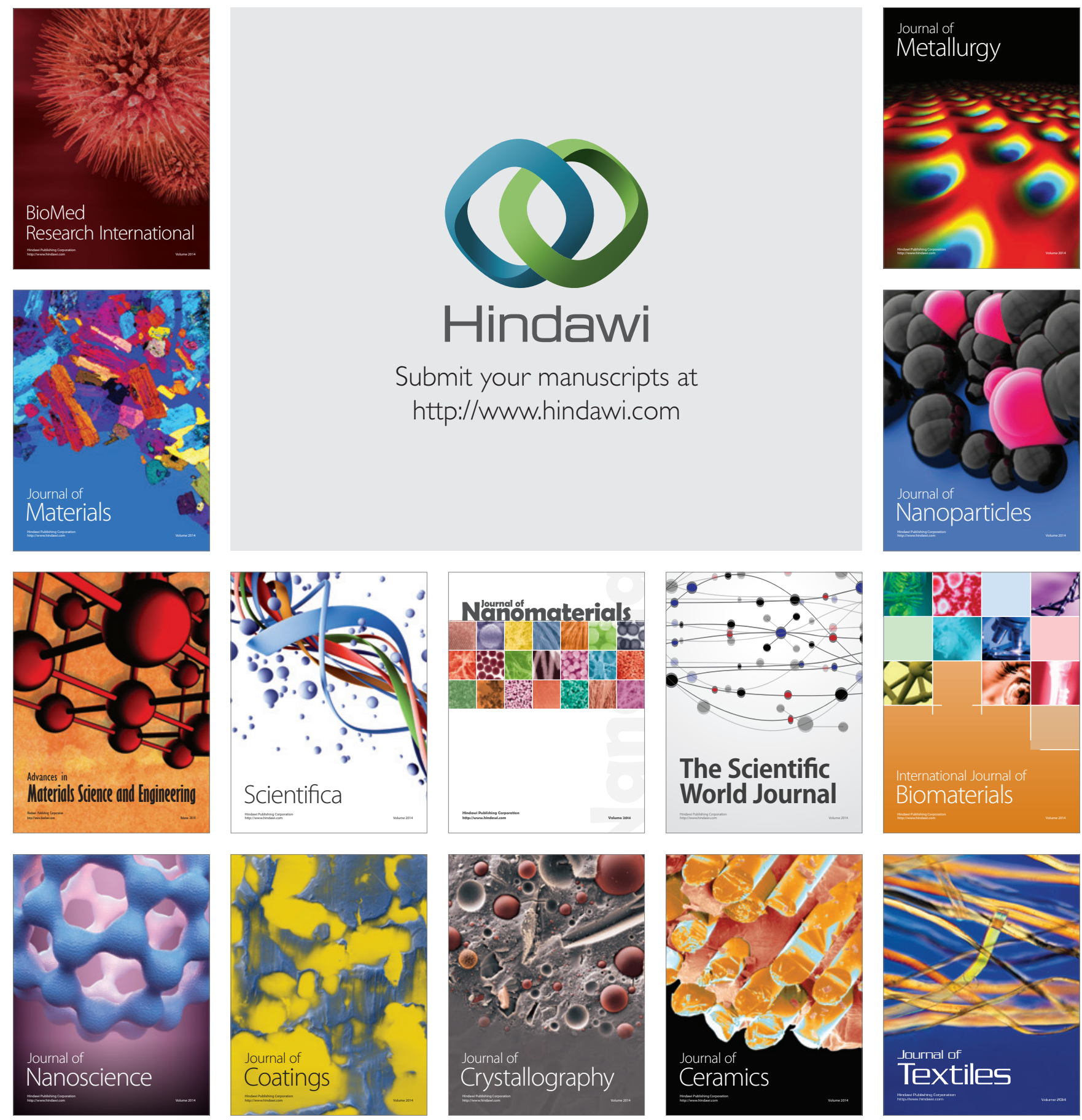